\title{
Bilio-bronchial and bilio-pleuro-bronchial fistulas of hydatic origin
}

\author{
Massine El Hammoumi, el Hassane Kabiri \\ Department of Thoracic Surgery, Military Teaching Hospital Mohammed V, Faculty of Medicine \\ and Pharmacy, Mohammed V University, Rabat, Morocco
}

Kardiochirurgia i Torakochirurgia Polska 2021; 18 (4): 239-246

\begin{abstract}
Bilio-bronchial fistulization is a rare complication of neglected liver hydatid cysts ruptured in the thorax by anatomical contiguity. Because of the bronchopulmonary and hepato-biliary lesions that it can cause and in the context of severe infection, the morbimortality remains high in these fragile patients. The diagnosis is based on clinical arguments: biliptysis mainly with a hepatothoracic syndrome, imaging data showing the fistulous path, and especially bronchial and biliary endoscopy. The pretherapeutic stage aims at correcting the hydrolytic, anemic and nutritional defects, but above all at controlling the hepatobronchial infection after removal of the biliary obstruction (endoscopic sphincterotomy) and by broad-spectrum antibiotic therapy as well as active respiratory physiotherapy. This preparatory step may be sufficient, otherwise surgical sanction is necessary in operable patients to establish the hepato-phreno-thoracic disconnection. The choice of the thoracic or abdominal approach depends on the initial and progressive lesion assessment and on the surgical strategy envisaged.
\end{abstract}

Key words: hydatid cyst, bronchial fistula, biliptysis, sphincterotomy.

\section{Introduction}

Bilio-bronchial fistulization is an abnormal communication of the bile ducts with the tracheobronchial tree. In most cases, bilio-bronchial fistulas (BBF) complicate hepatic hydatidosis; however, they can also be seen, but rarely, in other hepato-biliary conditions [1-3]. It is a dreadful complication of liver hydatid cysts ruptured in the thorax because of the broncho-pleuro-parenchymal and hepato-biliary lesions that it can cause with a high perioperative mortality.

The problem is above all that of the "highly infected" terrain and the choice of an adequate approach to treat the various pulmonary, diaphragmatic and hepatic lesions in a single step. Thoracotomy seems to be the best approach to control these lesions.

\section{Epidemiology}

The frequency of ruptured liver hydatid cysts in the thorax varies between $2 \%$ and $11 \%$ [4-8]. BBF by concomitant rupture of the liver hydatid cyst into the bile ducts and bronchi is seen in between $2.1 \%$ and $16 \%$ of all ruptured liver hydatid cysts in the thorax $[6,9,10]$.

\section{Pathological anatomy}

Anatomical lesions secondary to BBF were first described by Devé; these lesions involve two stages with different pressure gradients separated by the diaphragmatic septum [11]: a) Hepato-biliary lesions are the consequence of the natural evolution of the hydatid cyst, which most often sits at the level of the dome of the liver or at its posterior aspect. The content of the cyst is most often multivesicular and the pericyst is constituted by the surrounding hepatic tissue, which becomes dense and fibrous [12]. These hepatic lesions can range from simple erosion of the bile ducts to fistulization in the main bile duct or in a hepatic duct.

b) Diaphragmatic breach: the diaphragmatic breach is usually quite regular, highly variable in diameter, may be radial or roughly round, and is the starting point for pleuropulmonary lesions.

c) The fistulous pathway: the fistulous pathway communicates a hepatic cavity and a pulmonary and/or pleural collection which contain a real putrid "bouillie" made of bile, infected hydatid debris and pus [13].

d) Thoracic level: in the majority of cases, lesions involve the right lower lobe with or without involvement of the middle lobe, rarely the middle lobe alone or the left lower lobe. The lingula is exceptionally involved. The lesions observed are variable according to the state of the pleura: - In the case of symphyseal pleura, the hepatic cyst will rupture into the bronchi through a fistulous pathway or lead to an intra-pulmonary collection, or even total destruction of the affected parenchyma, 
- More rarely, the rupture occurs in the free pleura, resulting in a biliothorax or a secondary hydatidothorax. These pleural effusions may rupture secondarily into the bronchial tree or fistulate to the wall, constituting an "empyema of necessity" [14-16].

\section{Pathophysiology}

After implantation of the cyst in the liver, it will progressively increase in volume and asymptomatically over several months or years [17]. Several factors contribute to the development of bilio-bronchial fistulization (Figure 1):

a) The intrathoracic evolution of hepatic cysts, especially those in the convexity of the liver that are in contact with the diaphragmatic dome,

b) The pressure gradient between the abdomen and the thorax, which contributes to the aspiration of the liver cyst into the pleural cavity,

c) The mechanical compression of the diaphragm by the cyst and the respiratory movements causing repeated rubbing which leads to ischemia and then erosion of the diaphragmatic muscle, the infection of the hydatid cyst of the liver and the surrounding inflammatory reactions participate actively in the process of perforation of the diaphragm,

d) Sclero-inflammatory adhesions form, which eventually lead to fibrosis and subsequent atrophy of the diaphragmatic muscle fibers,

e) The bile in the cysts open in the bile ducts also plays a role through the chemical corrosion that it can cause in the diaphragm.

The BBF thus formed has no tendency to close spontaneously. The bile fluid also has a detrimental effect on the pleura and bronchial epithelium, causing irritation which promotes and maintains infection.

\section{Classifications}

Several classifications have been proposed; classification of Freixenet [18], of Yuste [19], of Dévé [11], of Mestiri [12] and of Gomez [20].

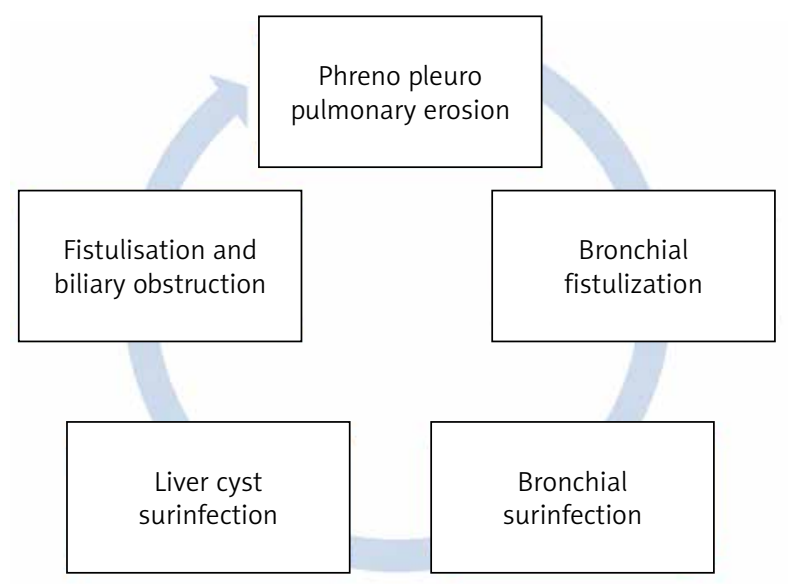

Figure 1. Vicious circle of bilio-bronchial and bilio-pleural fistulas

\section{Devé's classification}

This is the principal classification which recognizes three lesion groups:

a) BBF type I: it is the direct fistulization in the bronchi,

b) BBF type II: it is the constitution of an intermediate intraparenchymal collection,

c) BBF type III: it is the constitution of an intermediate intra-pleural collection.

\section{Mestiri's classification}

It distinguishes 4 lesion types and 9 subgroups:

a) BBF type I: direct fistula of the cyst into the bronchi:

- type I A: small bronchial fistulas,

- type I B: large-caliber bronchial fistulas;

b) BBF type II: intrapulmonary cavern:

- type II A: without bronchial fistula or bronchiolar fistula,

- type II B: with large-caliber bronchial fistula;

c) BBF type III: intrapleural intermediate pocket with encystment:

- type III A: without bronchial fistula,

- type III B: with bronchial fistula in the bronchi,

- type III C: fistulization towards the wall (empyema of necessity),

- type IV: rupture in the large pleural cavity:

- type IV A: Acute rupture: bilio-hydric pleurisy,

- type IV B: Secondary pleural hydatidosis.

This classification underlines the importance of bronchial fistulas without neglecting biliary fistulas, and deserves to be taken into consideration, because from the bronchial fistula follows the superinfection of the intermediate pocket and the original cyst, as well as the superinfection of the lung and the tracheobronchial tree.

\section{Gomez classification}

This is a simple classification that differentiates 5 evolutionary grades, based on the degree of trans-diaphragmatic extension of the liver hydatid cyst:

a) Grade 1: adherent cyst: there are adhesions between the surface of the liver cyst and the diaphragm but without perforation of the diaphragm.

b) Grade 2: Diaphragmatic traversal: the cyst perforates the diaphragm, but there is minimal invasion of the thoracic cavity.

c) Grade 3: secondary pleural hydatidosis: the cyst perforates the diaphragm and progresses into the thoracic cavity, or presence of daughter vesicles in the pleural cavity.

d) Grade 4: hydatid pneumonia: there is a cysto-bronchial connection, or there is only compression and atelectasis of the lung parenchyma.

e) Grade 5: chronic bronchial fistula: this is the stage of chronic bronchial fistula but without associated biliary fistula, which may be related to the natural evolution of a hydatid cyst of the liver or to a postoperative complication of an operated hydatid cyst.

In the light of these classifications, we propose a new classification of these lesions, which is more simplistic and 


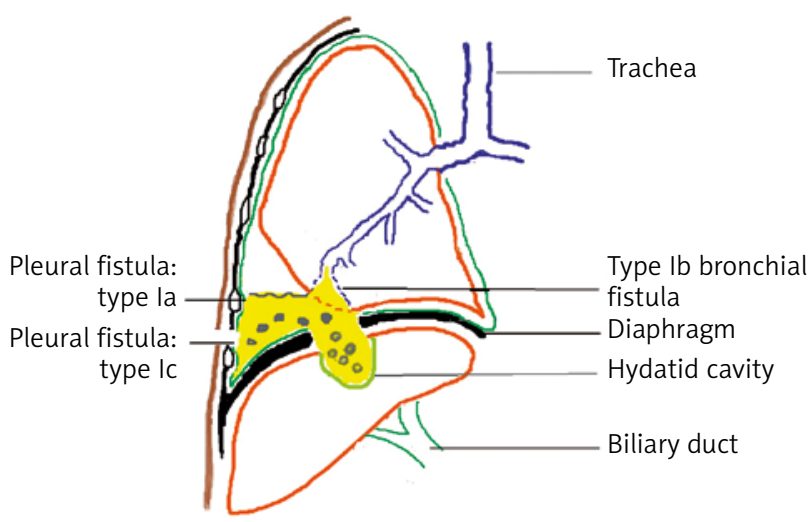

Figure 2. Descriptive figure of a type I bilio-bronchial fistula of the proposed classification

will allow an anatomical distribution but with the need of a large clinical study to approve this proposition.

Type I: bilio-pleural fistula (Figure 2):

a) type la: simple without associated bronchial fistula,

b) type Ib: complex with associated bronchial fistula,

c) type Ic: complex with associated parietal fistula (empyema of necessity).

Type II: bilio-bronchial fistula (Figure 3):

a) type Ila: small fistula,

b) type IIb: large fistula with intra pulmonary cavern.

\section{Clinical symptomatology}

Bronchial fistulization of hydatid cysts of the liver is always manifested by vomiting, which is the main symptom. This hydatid vomiting is almost always preceded by two phases: a prodromal phase and a premonitory phase [11]:

a) The prodromal phase; made of general signs and physical signs:

- fever, altered general condition.

- hepato-biliary signs; are not specific, in particular jaundice or sub-icterus which varies between $25 \%$ and $35 \%$ according to the series [12, 21, 22], right hypochondrium pain, angiocholitis,

- respiratory signs: cough, dyspnea, bronchial pneumonitis,

- signs of diaphragmatic irritation: hiccups

b) The premonitory thoracic phase; characterized by:

- coughing,

- pleural effusion, most often right,

- mucopurulent and then purulent sputum,

- hemoptysis,

- chest pain.

c) The hepato-pulmonary phase; characterized by hydatid vomiting. Hydatid vomiting is a suggestive sign of a ruptured hydatid cyst in the bronchi but does not indicate its pulmonary or hepatic location. Its frequency varies according to the series; it is said to range from $11.3 \%$ to $79 \%$ [21, 22]. It includes two varieties:

- hydatidoptysis which is the discharge of a "rock water" fluid or hydatid membranes,

- biliptysis or bilious vomiting is the main symptom of biliobronchial fistulization which can evolve into bronchial

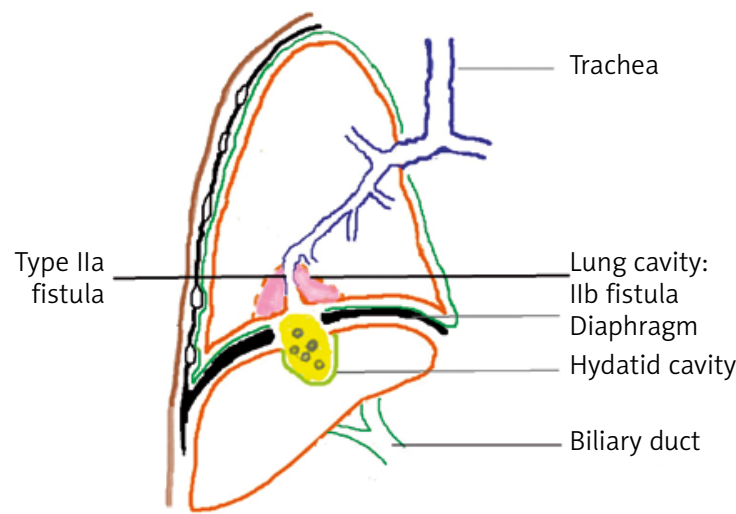

Figure 3. Descriptive figure of a type II bilio-bronchial fistula in the proposed classification

cholerrhagia. Its frequency varies according to the series; it is seen in between $12.5 \%$ and $77.8 \%$ of cases [21, 23].

\section{Complementary investigations \\ Biology}

Manifest biological inflammatory syndrome with hydroelectrolytic disturbances and cholestatic and cytolytic hepatic syndrome. Anemia of inflammatory type is almost constant. The search for bile salts in the sputum and/or pleural puncture fluid or bronchial aspiration helps to establish the diagnosis.

\section{Radiology}

Chest X-ray; which may show Figure 4:

a) pleural effusion especially right,

b) signs of bronchopneumonia, especially in the right lung base,

c) elevation of the diaphragmatic dome, especially on the right.

\section{Hepato-biliary ultrasound}

It studies the structure of the liver and the bile ducts in search of a dilatation or an obstacle, it also shows the hydatid cyst and allows it to be implicated in the genesis of this complication by showing the immediate vicinity between the hydatid cyst and the pulmonary lesions. It also allows visualization of the diaphragmatic breach in $70 \%$ of cases. It allows visualization of a pleural effusion.

It is of great interest in the diagnosis of bilio-bronchial fistula, by visualizing the diaphragmatic continuity solution as well as the origin, the path and the termination of the fistula, the search for a hepatic collection and a possible dilatation of the bile ducts [24].

\section{Thoracic computed tomography or magnetic resonance imaging}

Computed tomography (Figure 5) or MRI of the thorax is more efficient for an accurate bronchopulmonary and hepatobiliary lesion assessment. 


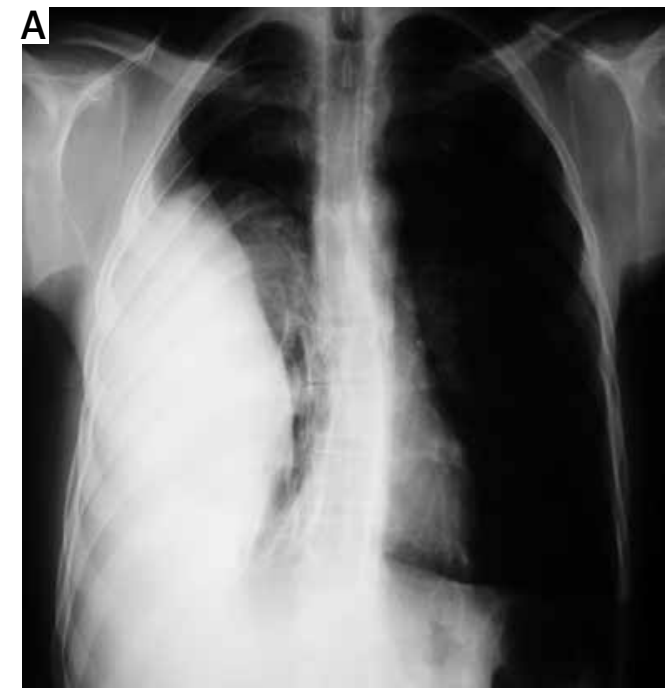

Figure 4. Chest $X$ ray of a post-hydatid bilio-pleurobronchial fistula from the front (A) and from the side (B)

\section{Retrograde endoscopic cholangiography}

Retrograde endoscopic cholangiography allows visualization of the fistula and search for a possible obstruction of the main biliary tract [25].

\section{Bronchial fibroscopy}

Bronchial fibroscopy can be useful for diagnosis and also to assess the severity of bronchial lesions, but it is rarely conclusive [26].

\section{Fistulography}

This is a simple examination that can quickly establish the etiological diagnosis; it allows visualization of a fistulous pathway communicating with a hepatic cavity and/or with the bronchial tree in the case of a cutaneous-cystohepato-bronchial fistula of hydatid origin. This examination is abandoned.

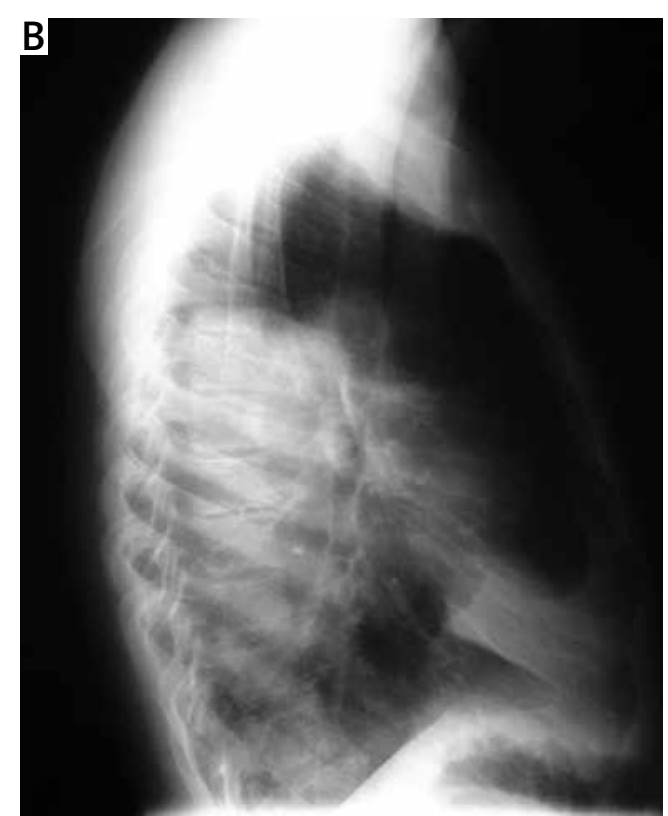

\section{Treatment}

The objective of the treatment of BBF is to dry up the fistula and to treat the cause of the fistula. It is a surgical treatment, with preoperative resuscitation [27], which consists of a re-equilibration of the hydro-electrolytic disorders caused by the biliary losses and increased by the infectious state, a fistulization in the pleura and respiratory physiotherapy.

The therapeutic attitude and the choice of the approach depend on the preoperative radio-clinical and biological assessment. The surgical treatment must fulfill the following objectives:

a) to treat intra-thoracic lesions, which sometimes require parenchymal excision,

b) to achieve hepato-diaphragmatic disconnection,

c) treat the hydatid cyst of the liver,

d) ensure freedom of the bile duct, and

e) repair the diaphragm,
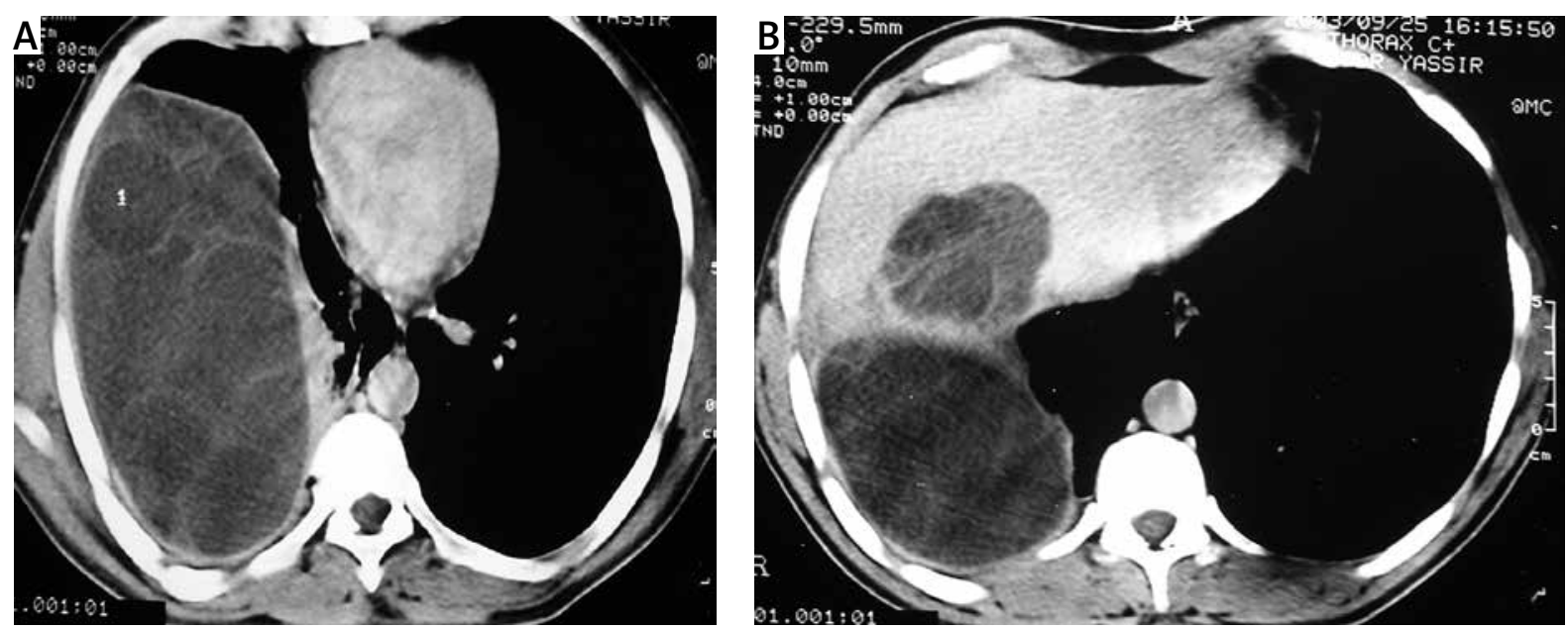

Figure 5. Computed tomography scan features (A, B) of a right hepato phreno pulmonary hydatidosis 
f) systematic drainage of the pleural cavity, the intrahepatic cavity and the interhepatic-diaphragmatic space.

\section{Surgical procedure}

1. Before the operation

This step is essential to determine the patient's operability and to anticipate the various operative risks. It includes the preoperative evaluation of the ventilatory function of the lung, the search for associated pathology, and the preparation of the patient for the operation [28, 29].

\section{Evaluation of the respiratory function}

Its objective is to search for a pre-existing respiratory impairment (COPD, PAH...).

Two examinations are fundamental: spirometry and blood gas measurements.

a) Spirometry evaluates alveolar ventilation by measuring pulmonary volumes and flows. The flow-volume curve provides information on both the mechanical and dynamic properties of the ventilatory system.

b) The measurement of blood gases assesses the efficiency of respiratory exchanges; the $\mathrm{PaO}_{2}$ evaluates the alveolar ventilation-perfusion ratio, the $\mathrm{PaCO}_{2}$ reflects the ventilation efficiency.

\section{Search for an associated pathology}

It allows one to foresee the deleterious consequences of perioperative hemodynamic variations and perioperative hypoxia.

\section{Preparation of the patient for the operation}

The surgical treatment can only be undertaken after the patient has been put in a condition, both on a general and pulmonary level, on which the postoperative course will depend. It consists of:

a) correction of the patient's nutritional and hydrolytic status,

b) systematic antibiotic therapy adapted and extended to the aerodigestive spectrum,

c) respiratory physiotherapy,

d) pleural drainage if effusion.

Preoperative endoscopic sphincterotomy, proposed by the majority of authors to decrease the flow of very productive fistulas (Figure 6) in order to avoid corrosive contact of the bile with the tracheobronchial tree [30, 31].

\section{Anaesthesia}

Selective intubation is imperative to protect the contralateral lung from any risk of flooding by bronchial secretions, but especially from bile or hydatid products. The most common are Carlens, White and Robertshaw tubes, which are distinguished from each other by the existence or not of a spur and by the side of the bronchus to be intubated.

Non-selective intubation should be avoided because of the risk of flooding the healthy lung on the side.
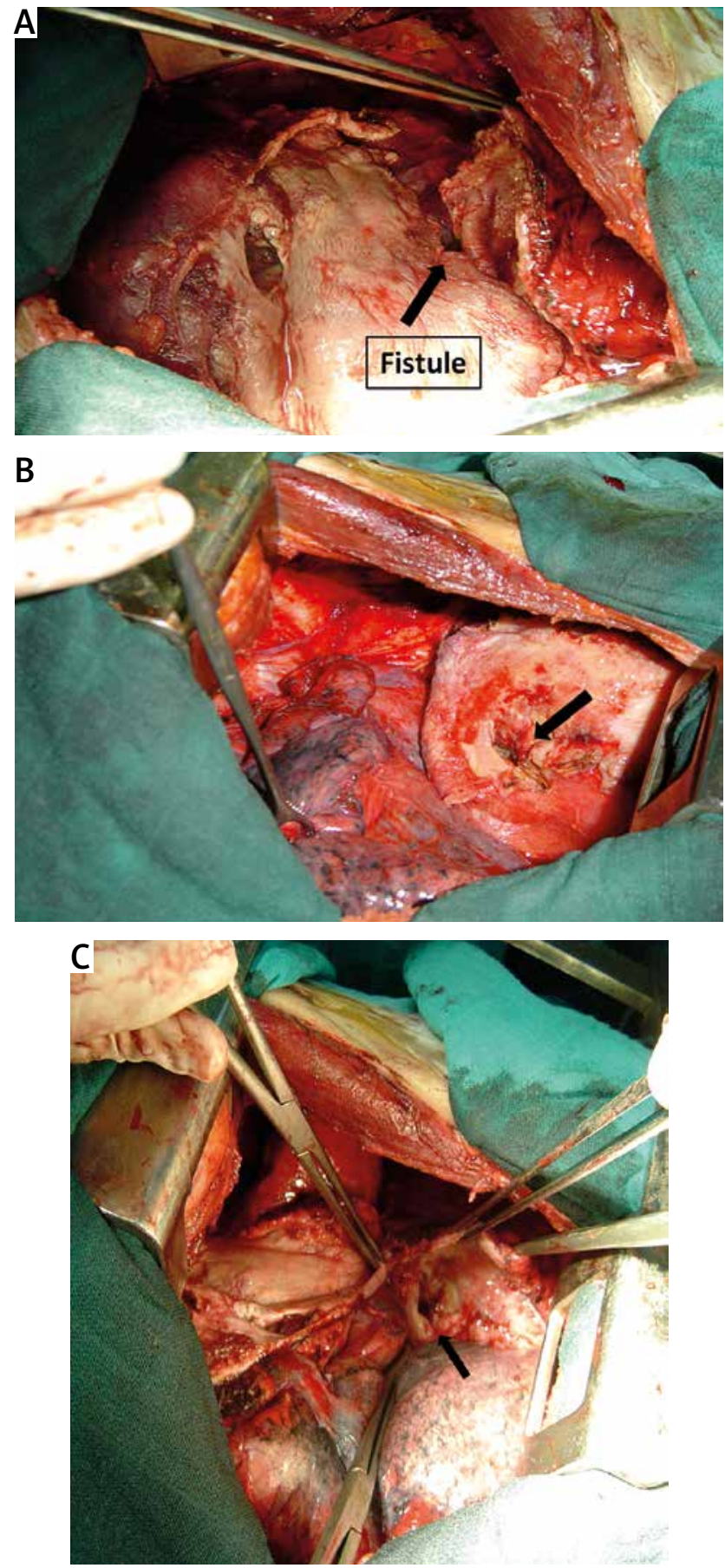

Figure 6. Operative views (A, B, C) of a low sited thoracotomy with a biliophrenic fistula (arrow) that can be visualized after phrenopulmonary deconnection

\section{Choice of approach}

The choice of the approach is a matter of preference and circumstance; the main thing is to be able to treat the three lesions by a single approach. There are many different approaches;

\section{Thoracotomy alone}

Demirleau [32] recommends complete cure of the pulmonary, diaphragmatic and hepatic lesions in a single step by low thoracotomy ( $7^{\text {th }}$ intercostal space) (Figures 7 and 8). 

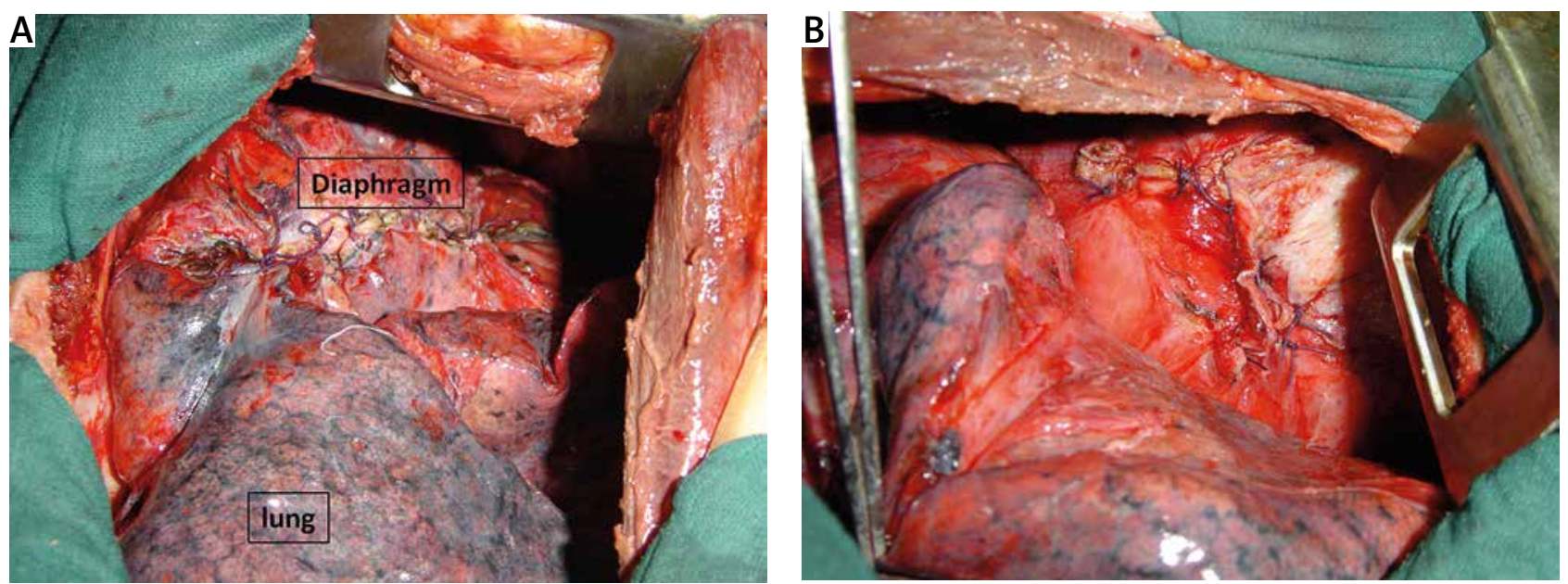

Figure 7. Operative views (A, B) of a low sited thoracotomy after repair of the biliophrenic fistula and hepatic lesions

Some authors think that it is the bronchial lesions that maintain the superinfection of the hydatid cyst of the liver, the pleural pouch and the broncho-parenchymal lesions, which therefore justify a thoracic approach [12, 33].

The thoracic approach is also recommended in the case of destruction of a lobe diagnosed preoperatively, or of pulmonary lesions (irreversible bronchiectasis or chronic pulmonary suppurations).

In small communications with little or no function, thoracotomy is sufficient.

\section{Thoraco-phreno-laparotomy}

Suggested by some authors [34] but it is mainly indicated in BBF of traumatic origin [35].

\section{Laparotomy alone}

In active biliary-bronchial fistulas with a large flow, the fistula can only be dried up by hepato-bronchial disconnection, which can only be carried out if the freedom of the bile ducts has been ensured, and to verify or ensure the freedom of the bile ducts, laparotomy is essential.

Some authors advocate an exclusive abdominal approach which allows hepato-biliary disconnection and cure

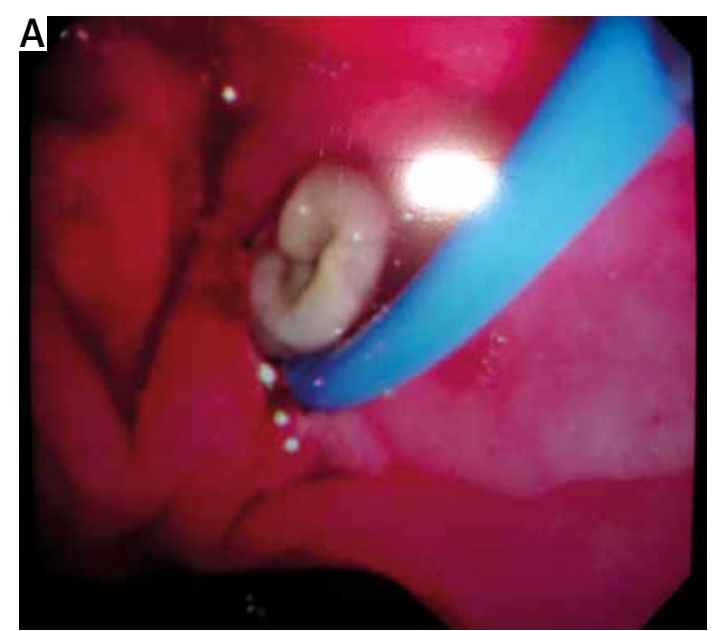

of the cyst(s) and ensures freedom of the bile ducts by drainage of the main bile duct if necessary [28]. Exclusive laparotomy is justified because it is intended for patients in poor general condition with impaired respiratory function.

Some authors think that the problem is essentially and above all hepato-biliary, and therefore they recommend a first laparotomy (right sub-costal), which allows intraoperative cholangiography to be performed, other possible liver cysts to be treated and, if necessary, the bile ducts to be freed by choledocotomy [27, 28].

- First thoracotomy followed by laparotomy.

This is proposed by some authors [22] and is a long procedure that is not well tolerated by patients whose general condition is precarious. It is unavoidable in case of biliary obstruction associated with evolving type II, III or IV thoracic lesions.

Some authors choose laparoscopy to repair abdominal and diaphragmatic lesions.

4. Repair of the lesions

\section{Liver}

The thoracotomy is performed in the $7^{\text {th }}$ intercostal space. First, the diaphragmatic fistula path is widened after excision of the sclerotic tissue. Then the periphery of the

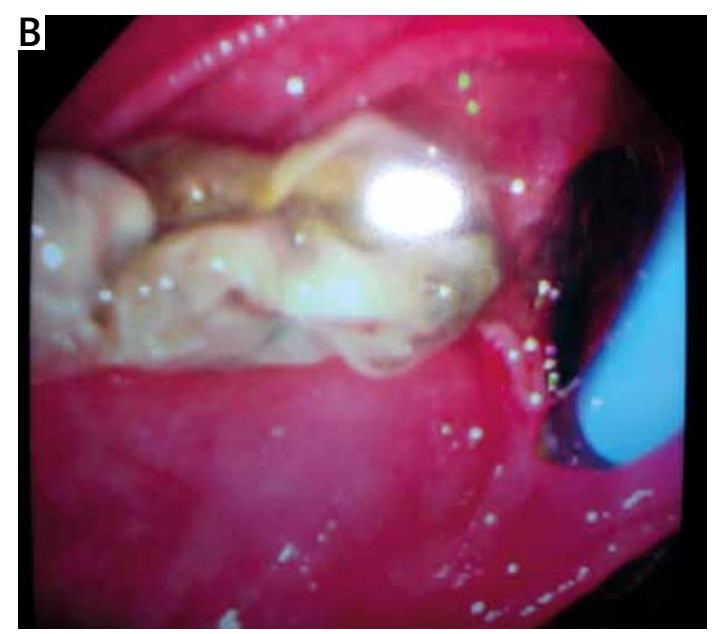

Figure 8. Per endoscopic view of a sphincterotomy showing the hydatid membrane exit 
hepatic pouch is detached from the diaphragm after opening the peritoneal cavity. This detachment considerably reduces the flow of the fistulas held open by the phreno-hepatic symphysis. Before treating the hepato-biliary lesions, the liver must first be freed and the fistulous path and diaphragmatic breach must be located. This release consists of sectioning the right triangular ligament, coronary ligament and falciform ligament, which allows good exposure of the cystic cavity and the diaphragmatic injury. Partial resection of the cystic sac followed by curettage of the remaining sac may be sufficient if there is no bilio-bronchial fistula.

a) Partial or total pericystectomy with or without epiplooplasty [36, 37].

b) Resection of the protruding dome, closure of fistulas.

c) Resections can be performed while remaining as sparing as possible. Segments VII and VIII are generally resected $[38,39]$.

d) Cysto-biliary disconnection.

In order to better explore the state of the bile ducts, intraoperative cholangiography and exploration of the main bile duct are the rule [2]; without being sure of the freedom of the bile ducts, it is imprudent to make a suture in order to pretend to close the bilio-cystic communication.

\section{Diaphragm}

After hepato-diaphragmatic disconnection, repair of the diaphragm does not generally pose any problems. Dissection of the phrenocostal adhesions allows phrenoplasty to be performed even if the wound is large. It will be done with a slow resorption suture (Figure 8).

\section{Lung}

The thoracotomy is performed in the $6^{\text {th }}$ intercostal space. The lung detachment must be performed rapidly in order to control the bronchial pedicle and avoid any risk of tracheobronchial flooding. Release of the lung from the diaphragm allows access to the fistulous path and emptying of the pulmonary and hepatic pockets. In the case of scleroinflammatory tissues irritated by bile, some authors consider that it is unwise to perform extensive pulmonary resections on scleroinflammatory tissues corroded by bile; it is necessary to limit resections to a minimum, especially since the lesions are often reversible [1, 2].

In the case of irreversible parenchymal lesions, segmental or lobar resections are clearly preferable to simple sutures of bronchial fistulas with pocket padding which are the source of repeated interventions in patients with an initially poor general condition [32, 40-42].

\section{The fistula pathway}

The diaphragmatic fistula will be closed by an X-stitch. If the fistula is large, the main biliary tract must be drained by a Kehr drain, and the cystic cavity will be drained by an interhepatic-diaphragmatic drain.

At the end of the procedure, the two drains connected by $\mathrm{a} Y$ connection are put in gentle suction until the appar-

\begin{tabular}{|l|}
\hline Diagnostic stage: \\
- Clinical: Biliptysis, hepato thoracic syndrome \\
- Paraclinical: radio-endoscopic-biological arguments
\end{tabular}

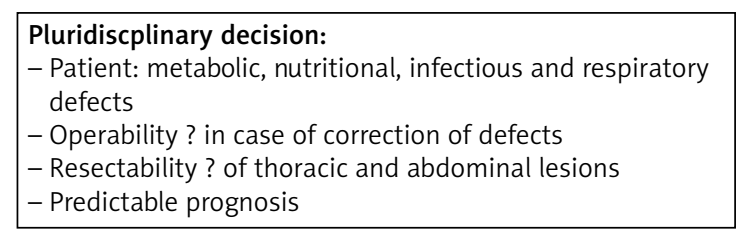

\begin{tabular}{|l|}
\hline Pre-therapeutic stage: \\
- Treatment of infection, metabolic and nutritional defects \\
- Pleural drainage and respiratory physiotherapy \\
- Endoscopic biliary disobtruction (Sphincterotomy)
\end{tabular}

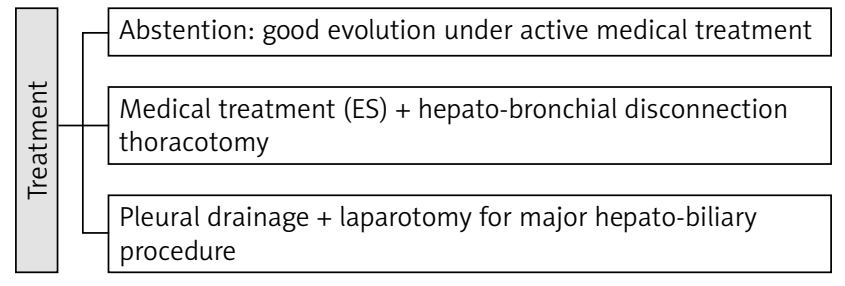

Figure 9. Summary diagram of the diagnostic and therapeutic approach of bilio bronchial and pleural fistula

ent exclusion of the thoracic drain, then the drains are left in siphoning for a few days (3 to 7 days).

\section{Results}

BBF of hydatid origin have a very poor prognosis; they are responsible for a high operative mortality rate which varies according to the series between $12.2 \%$ and $39.2 \%$ [11, 22, 27, 28].

Postoperative complications vary according to the series; a study carried out in our department found a rate of $12.7 \%$ of cases, dominated by infectious complications [1]; indeed, BBF surgery is a septic surgery, and the high incidence of postoperative infectious complications is therefore understandable. Therefore, every effort should be made to diagnose and manage these complications early to reduce the postoperative morbidity and mortality rate [22, 43].

\section{Conclusions}

The prognosis remains severe despite the improvement in resuscitation and surgical techniques. This shows the importance of early diagnosis and treatment and the establishment of a prophylaxis program based on the cooperation of veterinary services, public health services and the establishment of a special health education program based on prevention.

The choice of the approach and the types of resections must be adapted and discussed on a case-by-case basis. To summarize we present the scheme (Figure 9) and the main points to remember.

\section{Disclosure}

The authors report no conflict of interest. 


\section{References}

1. Kabiri H, Chafik A, al Aziz S, el Maslout A, Benosman A. Traitement des fistules biliobronchiques et bilio-pleuro-bronchiques d'origine hydatique par thoracotomie. Ann Chir 2000; 125: 654-659.

2. Kabiri EH, El Maslout A, Benosman A. Thoracic rupture of hepatic hydatidosis (123 cases). Ann Thorac Surg 2001; 72: 1883-1886.

3. Kabiri H, Al Aziz S, El Maslout A, Benosman A. L'Hydatidose diaphragmatique: a propos d'une série de 27 cas. Rev Pneumol Clin 2001; 57: 13-19.

4. Kabiri H, Caidi M, al Aziz S, el Maslout A, Benosman A. Surgical treatment of hydatidothorax. Series of 79 cases. Acta Chir Belg 2003; 103: 401-404.

5. Msougar Y, Lakranbi M, Bouchikh M, Ouadnouni Y, Maidi M, Fenan H, Smahi M, Achir A, Caidi M, Herrak L, Alaziz A, Benosman A. La place de thoracotomie dans le traitements des kystes hydatiques abdominaux rompus dans le thorax. Rev Mal Respir 2010; 27: 417-420.

6. Kilani T, Daoues A, Horchani H, Sellami M. Place de la thoracotomie dans les complications thoraciques des Kystes hydatiques du foie. Ann Chir Thorac Cardiovasc 1991; 45: 705-710.

7. Karydakis P, Pierrakakis S, Economou N, Ninos A, Raitsiou B, Bobotis EMolahias G, Antsaklis G. Traitement chirurgical des ruptures des Kystes hydatiques du foie. J Chir 1994; 131: 363-370.

8. Chehab F, Khaiz D, Lakhloufi A, Zahiri K, Abi Bouzidi A. Fistule bilio-bronchique d'origine hydatique A propos de 9 cas. Sem Hop 1997; 73: 800-804.

9. Low. VH. Transdiaphragmatic rupture of calcified hydatid cyst. Austral Radiol 1991; 35: 199-202.

10. Moumen M, El Fares F. Les Fistules bilio-bronchiques d'origine hydatiques. A propos de 8 cas. J Chir 1991; 128: 188-192.

11. Ezzedine H, Khalife M, Kanso M, Faraj W. Laparoscopic Management of hepatopulmonary fistula from hepatic hydatid disease. HPB 2019; 21: S605-S606.

12. Mestiri S, Kilani T, Thameur H, Sassi S. Les migrations thoraciques des kystes hydatiques du foie: proposition d'une classification. Lyon Chir 1987; 83: 12-16.

13. Sakhri J, Benali A, Letaief R, Derbel F, Dahmen Y, Ben Hadj Hmida R. Les kystes hydatiques du foie rompus dans le thorax: aspects diagnostiques et thérapeutiques. J Chir 1996; 133: 437-441.

14. Abi F, El Fares F. Fistules bilio-thoraciques: diagnostic aisé mais problèmes thérapeutiques et pronostiques. Maghreb Med 1989; 204: 11-16.

15. Goinard P, Pelissier G. A propos des fistules bilio-bronchiques d'origine hydatiques. Mém Acad Chir 1965; 91: 383-386.

16. Harrandou M, El Idrissi F, Al Aziz S, Cherkaoui M, Halhal A. Fistule CutanéoKysto-hépato-bronchique spontanée d'origine hydatique. A propos d'un cas. J Chir 1997; 134: 31-34.

17. Mzabi B, Bach-Hanba K. Traitement des Kystes hydatiques du foie ouverts dans les bronches. A propos de 24 cas. Mém Acad Chir 1978; 104: 404-412.

18. Freixenet JL, Mesters CA, Cugat E, Mateu M, Gimferrer JM, Catalan M, Callejas MA. Hepaticothoracic thransdiaphragmatic echinococcosis. Ann Thorac Surg 1988; 45: 426-9.

19. Yuste MG, Duque JL, Heras F, Sanchez E, Gonzalez SIma ML, Ramos G, Beltran De Heredia JM. Thoracic development of liver hydatid cysts, and its complications. A propos of 21 cases. Ann Chir 1984; 38: 153-157.

20. Gomez R, Moreno E, Loinaz C, De la Calle A, Castellon C, Manzanera M, Herrera V, Garcia A, Hidalgo M. Diaphragmatic or transdiaphragmatic thoracic involvement in hepatic hydatid disease: surgical trends and classification. World J Surg 1995; 19: 714-719.

21. Sakhri J, Ben Ali A, Letaief R, Derbel F, Dahmen Y, Ben Hadj Hmida R. Les kystes hydatiques du foie rompus dans le thorax. Aspects diagnostiques et therapeutiques. J Chir 1996; 133: 437-441.

22. Mzabi R, Bach Hanba K. Traitement des kystes hydatiques du foie ouverts dans les bronches. A propos de 24 cas. Mém Acad Chir 1978; 104: 404-412.

23. Boumghar $M$. Les fistules bilio-thoraciques d'origine traumatiques. J Chir 1986; 123: 457-462.

24. Jemmah $M$. Les fistules bilio-bronchiques d'origine hydatique. Thèse Med Rabat 1984; N0 389.

25. Bari S, Malik AA, Parray FQ, Samoon H, Munfat M, Bakshi IH. Delayed diagnosis of traumatic rupture of hydatid cyct of the liver. Int J Surg 2008; 6 : e18-e19.

26. Abi F, El Fares F. Fistules bilio-bronchiques: diagnostic aise, mais problèmes thérapeutiques et pronostiques. Maghreb Med 1989; 204: 11-16.

27. Guedj P, Morvant F, Solassol A, Guidoum Y. Les fistules bilio-bronchiques sévères des kystes hydatiques du foie. Lyon Chir 1958; 45: 161-163.

28. Moumen M, El Fares F. Les fistules bilio-bronchiques d'origine hydatique. A propos de 8 cas. J Chir 1991; 128: 188-192.

29. Moumen M, El Alaoui M, El Fares F. Les kystes hydatiques du foie. A propos de 670 cas dans 552 compliqués. Sem Hop 1993; 24: 722-725.
30. Rodriguez AN, Sanchez del Rio AL, Alguacil LV, De Dias Vega JF, Fugarolas GM. Effectiveness of endoscopic sphincterotomy in comlicated hepatic hydatic disease. Gastrointest Endosc 1998; 48: 593-597.

31. Vignote ML, Mino G, De La Matr M, De Dios JF, Gpmez F. Endoscopic sphincterotomy in hepatic hydatid disease open to the biliary tree. Br J Surg 1990; 77: 30-31.

32. Demirleau J. Traitement des kystes hydatiques du foie ouverts dans la plèvre. Mém Acad Chir 1965; 82: 470-479.

33. Kilani T, Danoues A, Horchani H, Sellami M. Place de la thoracotomie dans les complications thoraciques des kystes hydatiques du foie. Ann Chir 1991; 45: 705-710.

34. Goinard P, Pelissier G. A propos des fistules bilio-bronchiques d'origine hydatique. Mém Acad Chir 1965; 91: 383-386.

35. Chehab F, Khaiz D, Lakhloufi A, Zahiri K, Abi F, Bouzidi A. Fistule bilio-bronchique d'origine hydatique à propos de 9 cas. Sem Hôp 1997; 73: 800-804.

36. Galati G, Sterpetti AV, Caputo M, Adduci M, Lucandri G, Brozetti S, Bolognese A, Cavallaro A. Endoscopic retrograde cholangiography for intrabiliary rupture of hydatid cyst. Int J Surg 2006; 191: 206-210.

37. Mentes A, Yuzer Y, Ozbal D, Coker A, Itler T, Musoglu A. Omentoplasty versus introflexion for hydatid liver cysts. J R Coll Surg 1993; 38: 82-85.

38. Morel P, Robert IA. Surgical treatment of hydatid disease of the liver, a surgery of 69 patients. Surgery 1988; 104: 859-862.

39. Abu-Eshy SA. Clinical characteristics, diagnosis and surgical management of hydatid cysts. West Afr J Med 2006; 2: 144-152.

40. Crausaz PH. Surgical treatment of the hydatid cyst of the lung and hydatid disease of the liver with intrathoracic evolution. J Thorac Cardiovasc Surg 1967; 53: 116-129.

41. Boussofara M, Sallem MR, Raucoules-Aimé M. Anesthésie pour chirurgie du kyste hydatique du foie. EMC (Elsevier Masson SAS, Paris). AnesthésieRéanimation, 36-565-A-10, 2005: 7p.

42. Galindo R, Laraki A, Bartal M. A propos du traitement chirurgical des fistules bilio-bronchiques et bilio-pleuro-bronchiques d'origine hydatique. Ann Chir Thorac Cardiovasc 1975; 29: 147-149.

43. Nooman F, Mahmoudi A, Fodha MD, Boudokhane M, Hamdi A, Fodha M. Traitement chirurgical des kystes hydatiques du foie. EMC (Elsevier Masson SAS, Paris), Techniques chirurgicales - Appareil digestif 40- 775, 2013; 18p. 